\title{
Educação como tradição: a relação adulto- criança na antropologia culturalista de Margaret Mead e Ruth Benedict
}

Resumo: A criança tem feito parte de pesquisas antropológicas e educacionais na última década no Brasil. E é a partir desse interesse que esse artigo apresenta a educação como tradição na perspectiva antropológica. Esse artigo, então, tem como objetivo apresentar e discutir de maneira original a educação como tradição na compreensão das relações adulto-criança na perspectiva das contribuições da antropologia cultural. O artigo, então, tem como questões norteadoras: Qual o papel desempenham o adulto e a criança na perspectiva da antropologia cultural de Mead e Benedict? Há dinamicidade educacional no diálogo entre adulto e criança? Essa relação adulto-criança, na perspectiva da educação como tradição, está representada aqui nos trabalhos que Margared Mead e Ruth Benedict desenvolveram no início do século XX. Os trabalhos mostram a existência dos padrões de cultura, na preservação das relações e na formação do adulto ideal por meio da educação entre gerações.

Palavras-chave: Criança. Educação. Tradição. Antropologia.

\section{Education as tradition: relationship adult-child in cultural anthropology from Margaret Mead's and Ruth Benedict's works}

\begin{abstract}
The child has been part of educational and anthropological researches in last decade in Brazil. This paper aims to show education as tradition in the anthropological perspective. Moreover, this paper also aims to discuss in an original way the education as tradition for understanding the relationships adult-child in a perspective of the contributions of cultural anthropology. The paper puts the following questions: what is the place of adult and child in perspective of cultural anthropology from Mead's and Benedict's works? There is an educational dynamism in dialogue between adult and child? This relationship adult-child in perspective of education as tradition is represented hier in Margared Mead's and Ruth Benedict's works developed at the start of twentieth century. The works show existence of patterns of culture, preservation of relationships and formation of the ideal adult through intergenerational education.
\end{abstract}

Keywords: Child. Education. Tradition. Anthropology.

\footnotetext{
1 Doutora em Educação Escolar pela Universidade Estadual Paulista com estágio doutoral na Universidade Livre de Berlim na área de Antropologia da Educação. Pesquisadora Associada da Universidade Livre de Berlim e docente na Universidade do Estado de Minas Gerais/ Unidade Passos. E-mail: kalimonta@gmail.com
} 
criança tem feito parte de pesquisas antropológicas e educacionais nas últimas décadas no
Brasil (Tedrus, 1998; Nunes, 2002; Cohn, 2009; Pires, 2010). E é a partir desse interesse que
esse artigo apresenta a educação como tradição na perspectiva antropológica. Alguns trabalhos na Antropologia evidenciaram a relação adulto-criança e a educação como tradição, dos quais estiveram marcados em descrever o comportamento e personalidade de crianças e adultos. Essa relação foi estabelecida de maneira vertical e hierárquica, ou seja, cabia às crianças obedecerem às regras dos adultos, baseadas na lógica do conhecimento ancestral. É notável que a denominação dessa relação hierárquica esteja presente em muitos trabalhos antropológicos na primeira metade do século XX, sendo especificadas por relações dominadas por padrões, necessidades básicas, personalidades básicas, sistema de linhagens, categorias de idade, sistema de parentesco ou vínculos ao passado.

Para a elaboração deste artigo, debato as investigações realizadas por Mead e Benedict em etnografias com "povos primitivos" 2 , dos quais suas indagações e provocações consistiam em comparar esses povos às sociedades norte-americanas e europeias. Para tal, essas autoras desenvolveram suas teorias na tentativa de explicar o padrão de personalidade e costumes entre os grupos estudados. Os trabalhos de Mead e Benedict possibilitam refletir sobre a relação estabelecida entre adultos e crianças em uma educação para a tradição. Esse artigo, então, tem como objetivo apresentar e discutir de maneira original as contribuições da antropologia cultural para a compreensão das relações adulto-criança na perspectiva da educação como tradição. Nesse sentido cabem os seguintes questionamentos: Qual o papel desempenham o adulto e a criança na perspectiva da antropologia cultural de Mead e Benedict? Há dinamicidade educacional no diálogo adulto e criança?

Os grupos descritos pelas autoras eram apegados à tradição e ao passado e isso significa que o conhecimento era perpassado de geração em geração, dos mais velhos para os mais novos, no respeito à hierarquia e aos saberes já construídos por gerações anteriores. Nesses casos, a relação estabelecida entre adulto e criança era construída de maneira vertical, de cima para baixo, no respeito às ordens e às regras, com ou sem, mandos e desmandos, ordens e submissões, cordialidade e hostilidade, mas que deveriam preservar os costumes. De acordo com Benedict (2013), há padrões de personalidade que configuram as relações entre adultos e crianças. Para cada grupo existem características predominantes na constituição das relações e na formação do adulto ideal, tal é o interesse pela personalidade ideal. Enquanto para Mead (1979) há consonância entre padronização dos costumes, da moral e do desenvolvimento com a norma cultural de cada povo, cujo objetivo consistia em preservar a tradição.

${ }^{2}$ As aspas são do autor do artigo. Essas aspas são necessárias para identificar que os povos são denominados como primitivos, pois está de acordo com a denominação das autoras. 


\section{As contribuições de Margaret Mead: os mecanismos educacionais para preservação dos costumes e da tradição dos povos}

Margaret $\operatorname{Mead}^{3}$ foi uma das pioneiras no estudo da educação dos povos, investigando minuciosamente os mecanismos educacionais dos povos, de modo a realizar suas observações em bebês, crianças, adolescentes e adultos ${ }^{4}$, pois só de uma maneira contextualizada e geral do povo, seria possível compreender os comportamentos e atitudes daquele povo, principalmente, na relação adulto-criança. Influenciada pela Psicologia, pela teoria do Desenvolvimento Infantil e pela Antropologia Cultural, Mead teve interesse tanto nos estudos de personalidade, quanto no desenvolvimento das crianças até a vida adulta. Para isso, Mead focou na relação adulto-criança dos seguintes povos: Samoanos, Arapesh, Mundugumor, Tchambuli e Manus.

Há um padrão de crescimento natural dos bebês humanos, assim "há culturas como o Arapesh em que o rastejar (engatinhar) é recomendado antes do aparecimento dos dentes, ou como no povo balinês em que uma criança não pode colocar os pés no chão e, portanto, tem pouca liberdade fora do seu meio e dos cuidados da mãe" (MEAD, 1947, p. 72).

Essa padronização dos costumes, da moral e do desenvolvimento entra em consonância com a norma cultural de cada povo. Em Growing up in New Guinea, Mead ressalta que, para os estudos da personalidade e do ajustamento social, as crenças religiosas, hábitos sexuais, os métodos de disciplina, os objetivos sociais das pessoas que constituem a família da criança são constituintes da própria cultura e demonstram que o indivíduo dentro dessa cultura não difere dos outros da mesma idade ou sexo. Por isso, deve ser lembrado que

[...] em uma cultura como Manus, com apenas uma divisão sexual do trabalho entre os indivíduos (divisão do trabalho entre localidades que, é claro, ocorrer), sem qualquer sacerdócio com um grande corpo de conhecimento esotérico, sem qualquer método de manter registros extensos, a tradição cultural é simples o suficiente para ser quase inteiramente contida dentro da memória de um membro adulto médio da sociedade. (MEAD, 1930, p. 280, tradução nossa).

Em uma sociedade primitiva, o seu estrato social é homogêneo e simples, de modo que as etapas do desenvolvimento do indivíduo e/ou do grupo ficam evidentes, como a sua idade cronológica, a idade

\footnotetext{
${ }^{3}$ Margaret Mead (1901-1978) antropóloga norte-americana da Escola de Cultura e Personalidade. Ela sempre tentou aplicar à sociedade americana os conhecimentos adquiridos da Antropologia, denunciando problemas relacionados com a educação, a adolescência, a sexualidade, as condutas sociais, entre outros. Ensinou Antropologia na Universidade da Colúmbia e trabalhou como Conservadora de Etnologia no American Museum of Natural History. Tem como principais obras: Coming of age in Samoa, 1928, Growing up in New Guinea, 1930, Sex and Temperament, 1935. Realizou diversos trabalhos de campo entre os anos de 1925 a 1939, na Oceania, Nova Guiné, cuja finalidade consistia em observar as relações entre crianças e adultos, mais especificamente, entre filhos e mães, filhos e pais, crianças e mais velhos, e vice-versa. Tinha como foco observar as relações sociais, o tipo de afetividade manifesta e o modo segundo o qual os modelos de comportamento e as normas do grupo eram transmitidos de geração em geração. Estudou assim os Samoanos (1925), os Manus (1928), os Mundugumor, os Tchambuli (1931 - 1935), os Bali (1936 - 1939), os latmul (1938) da Nova Guiné e os Arapesh (1930).

${ }_{4}^{4}$ Mead utilizou o método comparativo, comparando assim as meninas da burguesia norte-americana com as meninas de diversas tribos. Segundo Erny (1982), ela se perguntava se o estudo da educação dos povos, então, dado o nome de primitivos não fornecia ideias próprias para melhorar a educação em seu próprio país, no caso os Estados Unidos da América. Embora uma de suas preocupações iniciais consistisse em estudar as adolescentes, Mead investiga minuciosamente os mecanismos educacionais dos povos, de modo a realizar suas observações em bebês, crianças, adolescentes e adultos, pois só de uma maneira contextualizada e geral do povo, seria possível compreender os comportamentos e atitudes dos adolescentes. Dentro dessas pesquisas há de ressal tar o grande destaque de Mead em observar as crianças e as relações de seus pais ou mais velhos para com elas. É nesse sentido que suas obras contribuíram para o estudo das atitudes de crianças e adolescentes.
} 
dos pais no momento do nascimento, ordem de nascimento, tipo de parto, seus costumes, pois são relativamente imutáveis.

Nesse tipo de sociedade há uma consonância na padronização dos costumes, desse modo, os Samoanos, os Arapesh, os Mundugumor e os Tchambuli foram denominados como pertencentes à cultura pós-figurativa ${ }^{5}$, ou seja, aquela em que as crianças aprendem, principalmente, a partir de seus antepassados. Nessa cultura, o conhecimento é passado de geração em geração e, por isso, o passado é muito importante na preservação dos costumes, assim a cultura depende das três gerações. Exceção para os Manus que tiveram toda a sua cultura reconfigurada pelos jovens.

Na década de 1920, Mead viaja até a Ilha de Tau localizada no sul do Oceano Pacífico, entre o Havaí e a Nova Zelândia, para estudar os Samoanos, a fim de realizar suas observações e responder às indagações referentes à questão da adolescência, tão presente nesse período. Estimulada por Franz Boas, Mead resolve percorrer um longo caminho e ir até Samoa. Por que os Samoanos foram os escolhidos? A autora argumenta que somente realizando a comparação entre os costumes dos Samoanos e dos norteamericanos poderia responder às indagações em relação à adolescência dos norte-americanos, como por exemplo, a reação à repressão, o temperamento das meninas, a rebeldia, e,

[...] por causa do problema particular que nos propusemos a responder, este conto de outro modo de vida está preocupado principalmente com a educação, com o processo pelo qual o bebê chegou sem cultura em cena humana, torna-se um membro adulto de pleno direito em sua sociedade. Será concedida maior importância às maneiras pelas quais a educação Samoana, no seu sentido mais amplo, difere da nossa. E a partir deste contraste que pode ser capaz de transformar, feito recentemente e vividamente autoconsciente e com autocrítica, para julgar novamente e talvez de modo diferente da educação que damos aos nossos filhos (MEAD, 1928, p. 13, tradução nossa).

Os Samoanos são descritos na obra Coming of Age in Samoa ${ }^{6}$. Mead relata que entre os Samoanos da Ilha de Tau a relação entre adulto - criança ocorre entre o mando dos adultos e a subordinação das crianças, de modo que a hierarquia seja respeitada. A dança serve como um fator educativo, cujas funções consistem em manter a subordinação das crianças e reduzir a sua timidez. As crianças são ensinadas a ter submissão aos mais velhos, e é, por isso, que desde os quatro ou cinco anos de idade, já lhes são definidas as suas tarefas, pois isso permite criar um significado na estrutura de toda a sociedade Samoana, em consequência disso, as crianças aprendem o seu lugar na tribo.

As crianças Samoanas aprendem tarefas, segundo Mead (1928), como cuidado com os bebês, além de outras técnicas simples como tecer bolas de folha de palmeira, subir em árvore de coco, a jogar

\footnotetext{
${ }^{5}$ Margaret Mead em Culture and commitment. A study of the generation gap procurou explicar as culturas primitivas e modernas por meio de três tipologias de cultura por ela criada, dos quais são a pós-figurativa, a con-figurativa e a pré-figurativa. Na cultura pós-figurativa, os educandos aprendem primordialmente de seus ancestrais, e fazem parte dessa cultura os povos primitivos e redutos religiosos e ideológicos extraindo do passado os valores e crenças. Na cultura con-figurativa as crianças e adultos aprendem de seus pares respectivos, e fazem parte dessa cultura as grandes civilizações, capazes de incorporar mudanças. A cultura pós-figurativa tem como característica a nova autoridade assumida pelos jovens. Esses três tipos de cultura, de acordo com Mead, permitem ampliar a ideia que se faz da criança e superar o viés determinista e reducionista que impera nas pesquisas com crianças.

6 Para realizar esse estudo comparativo, Mead optou por observar essa pequena localidade, cuja população havia apenas 600 pessoas, das quais 68 eram meninas com idade entre nove e 20 anos. Para ela seria mais interessante passar nove meses acumulando dados e conhecimento profundo e detalhado de todas as meninas adolescentes da comunidade, priorizando a descrição e a análise dos dados. No entanto, para o estudo desses adolescentes, Mead realizou um estudo completo e contextualizado de toda a tribo, iniciando a sua descrição falando sobre as crianças, pois na escala de maturação, os bebês estão iniciando sua formação e aprendizagem.
} 
uma série de jogos em grupo, a cantar as músicas da tribo, a arrumar a casa, pegar o lixo, trazer água do mar, espalhar óleo de copa para secar, a ir a uma casa vizinha buscar algum alimento e a implorar por favores dos parentes. Essas tarefas são incumbidas às meninas, já que aos meninos são dadas tarefas altamente eficientes, como caçar e pescar.

Em Samoa, na educação das crianças, já é imposta uma distinção entre meninos e meninas desde pequenos, ficando a cargo das meninas dominarem várias técnicas de cuidado com a casa e de aprendizagem do artesanato, e aos meninos a preocupação de um dia se tornar um matai . No entanto, ao longo da educação da menina, é preciso que ela mantenha bom equilíbrio e o virtuosismo, pois as chances de a menina danificar a sua imagem é muito grande, prejudicando assim o seu casamento. Embora as crianças tenham dificuldades em compreender o sentido das instruções do mundo adulto, deve-se respeitar a hierarquia e as regras para que possa suceder à alta classe social.

Além dos Samoanos, Mead (1979) descreve a relação adulto-criança entre os Arapesh, os Mundugumor e os Tchambuli na obra Sexo e Temperamento. Para a autora, entre esses três povos existem padrões de comportamento que norteiam todo o crescimento e desenvolvimento de seu povo.

Os Arapesh vivem tanto nas montanhas como nas planícies, mas com estilos de vida diferentes na Nova Guiné. Os Arapesh da planície vivem em casas espaçosas, com fartura de alimentos e são mais tranquilos, enquanto os da montanha vivem em casas pequenas e frágeis e tem pouca comida. No entanto, encaram a vida como uma aventura em observar cuidadosamente as regras de crescimento de tudo o que está ao seu redor: das crianças, dos porcos, dos inhames, dos carás, dos cocos e dos sagus.

A vida dos Arapesh se organiza dentro da dinâmica em que homens e mulheres fazem coisas diferentes, pois aos homens é concedida maior autoridade, enquanto para as mulheres é concedida a exclusão das cerimônias, a fim de guardá-las dos maiores segredos da tribo para não prejudicar nem a elas, nem os seus filhos, consequentemente, a tribo. Essa diferença entre os sexos já se inicia na infância que prevalecerá por toda a vida deles. Os papéis para cada sexo, meninas e meninos, já lhes é incumbido quando pequenos.

Mead (1979) ressalta ainda que as meninas pequenas são úteis para transportar, capinar, recolher alimentos, carregar lenha e trabalhar nas festas, sempre no trabalho em grupo. Já os meninos possuem outras funções que realizam individualmente, apenas com o acompanhamento do pai ou irmão mais velho, como uma expedição de caça, ir à mata para juntar ervas ou trepadeiras, ou cortar madeiras para a construção de casas.

Dessa forma, para compreendermos um pouco melhor sobre essa relação, Mead (1979) traz duas questões que permitem pensar sobre a educação dos Arapesh e a relação que se constrói entre o adulto e a criança: De que maneira o bebê Arapesh é moldado e formado para transformar-se na personalidade tranquila, delicada e receptiva que é o adulto Arapesh? Quais são os fatores determinantes na educação

7 Um nome que irá torná-lo um membro da Fono, o conjunto de chefes, o que lhe dará o direito de beber kava com os chefes, para trabalhar com chefes ao invés de trabalhar com jovens homens, para sentar-se no interior da casa. 
inicial da criança, que asseguram que será plácida e satisfeita, não agressiva e não iniciatória, não competitiva e receptiva, cordial, dócil e confiante?

Os fatores determinantes que moldam e formam a criança se encontram em uma sociedade simples e homogênea, onde as crianças quando crescem terão os mesmos traços de personalidade de seus pais. Entre os Arapesh, há uma relação que vai além da imitação, pois prevalece uma relação delicada entre crianças e adultos, ou seja, entre filhos e pais, de modo que "a criança é alimentada, posta para dormir, disciplinada, ensinada a ter autocontrole, acariciada, punida e encorajada, e o ajustamento adulto final" (MEAD, 1979, p. 64). Ressalta-se que a maneira cordial e delicada como os homens e mulheres tratam seus filhos é um dos pontos mais significativos, para o desenvolvimento da personalidade do adulto, que são vivenciados na infância.

Durante os primeiros meses de vida, a criança nunca está longe dos braços de alguém. Quando a mãe passeia, carrega o bebê em sua cestinha de rede apoiada em sua fronte, ou pendurado, sob um seio, numa tipoia de córtex. Este último método é o costume litorâneo; quanto ao modo da cesta de rede, é usado pelos habitantes das Planícies; as mulheres das montanhas usam ambos os métodos, dependendo em grande parte da saúde da criança (MEAD, 1979, p. 64).

Entre os Arapesh, os bebês e as crianças são moldados para se transformarem na personalidade tranquila, delicada e receptiva à semelhança do adulto. Nessa sociedade simples e homogênea, a relação adulto-criança acontece por meio da cooperação e da cordialidade, de modo que "a criança é alimentada, posta para dormir, disciplinada, ensinada a ter autocontrole, acariciada, punida e encorajada, dando ajustamento ao adulto final" (MEAD, 1979, p. 64).

Há um sentido de atemporalidade nos costumes dos Arapesh e um desespero e medo de que o conhecimento possa ser perdido para sempre. Eles viveram sempre "acreditando num único passado, uma época de fábula, um tempo atemporal de distância, em um lugar onde cada rocha e árvore serviram para restabelecer e reafirmar que o passado é imutável, os velhos, os de meia-idade, e o jovem recebem e transmitem o mesmo conjunto de mensagens" (MEAD, 1970, p. 6, tradução nossa). Essa característica de perpetuação dos costumes faz dos Arapesh um povo cuidadoso com as crianças, cuja finalidade de sua educação é exprimida na base da confiança.

Os Mundugumor, ao contrário, dos Arapesh manifestam relações de competitividade e hostilidade entre eles, principalmente, entre adultos e crianças. Todo o sentimento de hostilidade e competição perpassa a relação entre as crianças e os mais velhos.

A sociedade dos Mundugumor não está organizada em clãs, logo não há uma comunidade legítima, de modo que existem vários lugares nomeados, vivendo em diferentes lugares. A organização social dos Mundugumor "se baseia na teoria de que existe uma hostilidade natural entre todos os membros do mesmo sexo, e na suposição de que os únicos laços possíveis entre os membros do mesmo sexo passam através de membros do sexo oposto" (MEAD, 1979, p. 178). Dessa maneira a organização social se constitui naquilo que chamam de corda, pois ao invés de se organizarem os indivíduos em grupo patrilineares ou matrilineares, de modo a unir irmãos do mesmo grupo, com seu pai e sua mãe, eles se separam. Outro ponto da organização social é a poliginia, pois ter um grande número de esposas significa 
riqueza e poder. No entanto, salienta Mead (1979), a existência da poliginia como um ideal de poder significa conflito e violência entre irmãos, já que os homens de todas as gerações podem casar com várias mulheres, sejam mais velhas ou mais novas, sejam irmãs ou primas.

A hostilidade é um sentimento marcante entre pai e filho, entre irmãos, meio-irmãos, transformando em incertezas a organização social dessa tribo. Para compreender como em uma sociedade pode existir tanta hostilidade e desconfiança, Mead (1979) salienta que é necessário considerar a vida econômica e cerimonial desse povo.

Os Mundugumor são ricos; têm terras em superabundância, seus barads piscosos estão cheios de peixes; geração após geração de ancestrais plantaram coqueiros e arequeiras. Têm copiosos suprimentos de sagueiros; seus campos produzem o fumo tão valorizado por seus vizinhos. Suas palmeiras são tão abundantes que eles dizem casualmente serem os morcegos os plantadores (MEAD, 1979, p. 189).

Essa vida econômica indica que não há necessidade de cooperação entre as famílias, pois aos homens, o sentido de competição e hostilidade é forte e são expressos de modos econômicos, tendo, como causa principal das disputas, as mulheres.

Isso significa que todo o mecanismo educacional desse povo será permeado de um mundo hostil, de inimizades e competições, "mundo onde a maioria dos membros do seu próprio sexo serão seus inimigos, onde seu melhor instrumento para o êxito deve ser a capacidade para a violência, para ver e vingar insultos... Desde a sua concepção, quando a mulher diz estar grávida, a criança Mundugumor é rejeitada” (MEAD, 1979, p. 189). Quando o bebê nasce, há continuidade no sentimento de hostilidade, "quando um nenê chora, não é alimentando imediatamente, em vez disso, algum curioso recorre ao método usual de acalmar crianças inquietas, o arranhar as costas" (MEAD, 1979, p. 194). As mães não sentem nenhum prazer em alimentar o seu filho, ficando apenas a tarefa de alimentá-lo até o fim do choro, assim logo quando terminam, as crianças são recolocadas na cesta.

Após aprenderem a andar, as crianças aprendem as diferenças existentes entre meninos e meninas na tribo, pois fica evidente a preferência pelas meninas. As meninas são ensinadas a serem desejáveis, são enfeitadas com brincos, colares, cintos de conchas, usam saias de palha e são sempre exibidas nos braços do pai. Enquanto que os meninos, eles são deixados nus até os sete e oito anos de idade e sem enfeites.

As diferenças entre meninos e meninas marcam o aprendizado dessas crianças Mundugumor. É ensinado desde pequenos que os ensinamentos dos meninos devem partir da mãe, enquanto os ensinamentos da menina devem partir do pai: "Como é pressuposto que a menina assuma a identidade social da avó paterna, deve aprender com o pai, que a conhece melhor do que a mãe, os detalhes de seu parentesco, e o mesmo vale para o menino - cabe à mãe instruí-lo nas suas relações de corda" (MEAD, 1979, p. 201). No entanto, à medida que crescem, a menina fica mais próxima de uma menina mais velha e os meninos abandonam o lar. Essas relações acontecem para a manutenção da organização social constituída naquilo que chamam de corda.

Segundo Mead (1979), o mundo é apresentado à criança desde que nasce, como um lugar onde existe grande número de relações fixas, com um padrão de comportamento apropriado para uns e 
altamente inadequado e insultante para outros. Os Mundugumor padronizaram o comportamento de homens e mulheres como ativamente masculinos e viris e sem quaisquer das características de uma mulher suave e feminina. Essa falta de questionamento e de consciência parece ser condição essencial para a manutenção da cultura pós-figurativa, decorrente da vida hostil e desconfiada, marcada por um crescimento infantil sem questionamentos, logo para a manutenção dos clãs e de seus costumes.

Após estudar os Arapesh e os Mundugumor, Mead (1979) sente-se descontente ao perceber que havia uma padronização no comportamento dos dois grupos estudados. Para Mead (1979), era preciso um povo que diferenciasse das etnografias tradicionais, ou seja, que os comportamentos não estivessem embasados em certas configurações tradicionais, principalmente, em relação ao homem e à mulher. Em decorrência disso, Mead (1979) decide pesquisar os Tchambuli. Esse povo está localizado perto do Rio Sepik, é uma pequena tribo de poucas pessoas, das quais apenas 500 falam a sua língua, sendo que uma parte fala com sotaque diferente. Vivem em três aldeias à beira do Monte Tchambuli com as casas erigidas em altas estacas, de modo que a vida cotidiana segue um ritmo sossegado da pesca e do trançado das mulheres e das atividades cerimoniais dos homens. A tribo toda cessa seu trabalho no momento da festa ou da dança de máscaras, dando grande importância para a arte e a imaginação.

Nos Tchambuli, há uma relação contrastante entre homens e mulheres, explica Mead (1979), mas que na verdade impõe um padrão característico para a manutenção da organização social desse povo. $O$ contraste se dá em relação ao homem e à mulher e é isso que mantém as relações, mesmo que contrastantes, entre adultos e crianças. Como a relação é poligênica e o homem compra sua esposa, está implícita a predominância de sua dominação, entretanto, o poder concentra-se na mulher, logo essa sociedade apresenta contradições,

[...] sob formas patriarcais, as mulheres dominam a cena. Com uma personalidade social muito mais dominadora e definida do que é usualmente desenvolvida nas mulheres, mesmo sob a matrilinearidade, as mulheres são teoricamente sujeitas aos homens; foram, na verdade, compradas e pagas, fato que é mencionado com freqüência. (MEAD, 1979, p. 259).

Consequentemente, o menino Tchambuli cresce dentro de dois conjuntos de ideias conflitantes, relata Mead (1979, p. 260), "ouve dizer que seu pai comprou sua mãe, ouve falar quanto seu pai pagou por sua mãe e quanto recolherá agora para pagar pela jovem esposa de seu filho". Instala-se, então, um conflito do próprio ajustamento psicossocial do menino, pois,

[...] sua sociedade lhe diz que ele governa as mulheres, sua experiência mostra a cada passo que as mulheres esperam governá-lo, como governam seu pai e seu irmão. Entretanto, a verdadeira dominância da mulher é muito mais real do que a posição estrutural dos homens, e a maioria dos povos Tchambuli se ajustam a isso, habituam-se a esperar as palavras e os desejos das mulheres (MEAD, 1979, p. 260).

As crianças crescem dentro de um conjunto de ideias conflitantes, e instala-se assim, um conflito psicossocial no menino que se transforma em evidentes homens desajustados, sujeitos a acessos maníacos, histéricos e neurastênicos. Por outro lado, as meninas se transformam em mulheres sossegadas e não dominadoras. Esse desajustamento de personalidade torna-se mais evidente nos homens, porque a sua educação foi permeada por sentimentos de exclusão e abandono, enquanto, as mulheres tiveram uma 
relação de aproximação e carinho com as outras mulheres da tribo. Essa relação dos adultos que se instalou desde a infância marcou o comportamento de homens e mulheres da tribo, sejam de submissão ou de dominação. Mesmo com papéis invertidos, no qual o homem pensa ser o dominador quando compra a sua esposa, e a mulher que se submete às exigências do marido, mas ao mesmo tempo manda no local em que mora, demonstra-se que a inversão de papéis só acontece, porque na infância as crianças foram criadas com contradições dos papéis dos homens e das mulheres, influenciando assim toda a educação e seu modo de viver.

Por isso, sejam quais forem os povos, para Mead há uma estrutura ou padrão de personalidade que se configura por meio de mecanismos educacionais de atitudes e comportamentos, marcando assim a educação daquele povo e a relação entre adultos e crianças, instaurada hierarquicamente, cujo mentor e condutor daquela cultura é o adulto.

A relação adulto-criança dos Samoanos, Arapesh, Mundugumor, Tchambuli e Manus demonstram que relações entre homem e mulher são construídas desde a infância. Essas relações em sua maioria demonstram a subordinação da mulher para com o homem, muitas vezes ligadas ao cuidado da casa e da família. $\mathrm{O}$ ensinamento nesses povos que é passado de geração para geração considera que a menina desde a infância deva ser educada para ser calma, dócil e gentil, ou seja, para perpetuar um padrão de comportamento de homens como ativos e viris e mulheres como suaves e femininas.

\section{As contribuições de Ruth Benedict: o conceito de patterns nas relações adulto- criança}

Benedict $^{8}$ foi menos proeminente nos estudos com crianças e, principalmente, nas relações adulto-criança, mas que, todavia, contribuiu de maneira significativa para o desenvolvimento do conceito patterns (MEAD, 1979) e a transmissão de costumes entre adultos e crianças. Em Padrões de Cultura, Benedict (2013) debate sobre a questão da educação e da relação adulto-criança para a adaptação aos padrões e critérios tradicionalmente transmitidos de uma geração para outra na sua comunidade.

Desde o nascimento do indivíduo, os costumes da sociedade em que ele nasce moldam sua experiência e seu comportamento. Quando aprende a falar, ele é a pequena criatura de sua cultura, e quando se torna adulto e pode participar das atividades dela, os hábitos, as crenças e as impossibilidades dessa cultura são também os hábitos, as crenças e as impossibilidades dele. Toda criança que nascer no grupo desse indivíduo há de compartilhar tais hábitos, crenças e impossibilidades, e nenhuma criança nascida num grupo no lado oposto do mundo poderá adquirir sequer a milésima parte deles. Não há problema social que nos caiba compreender mais do que este do papel do costume (BENEDICT, 2013, p. 14).

\footnotetext{
8 Ruth Benedict (1887-1948) foi uma antropóloga norte-americana da Escola de Cultura e Personalidade com quem desenvolveu pesquisas com Margared Mead. Benedict introduz o tema de modelos culturais e apresenta uma visão dinâmica de cultura centrada na ideia de totalidade cultural. Destaca dois padrões culturais de base: o padrão apolíneo, de tipo equilibrado, ordenado e harmonioso e com uma propensão para o conformismo e para a arte; e o padrão dionisíaco, mais violento, desordenado, conflituoso e com uma profunda tendência para a guerra. Tem como principais obras: Padrões de Cultura (1934) e O crisântemo e a espada (1946).
} 
O conceito de patterns $^{9}$ proposto exprime que cada civilização escolha um imenso arco de possibilidades (elementos, instituições, tendências, motivações, comportamentos), de modo que a cultura seja definida por um homem ideal, por uma personalidade aprovada, sendo uma forma coerente e orientada na sua totalidade. Logo,

[...] a imensa maioria dos indivíduos nascidos numa sociedade adota o comportamento prescrito por essa sociedade, sejam quais forem as idiossincrasias de suas instituições... A maioria das pessoas é moldada conforme a sua cultura porque sua bagagem intelectual original é extremamente maleável. Elas são plásticas à força moldadora da sociedade onde nasceram (BENEDICT, 2013, p. 173).

Esse conceito é desenvolvido por Benedict ao descrever os Pueblo, os Zuhni, os Dobu, os Kwakiutl, os japoneses e os Ojibwa. O Pueblo é uma das diversas etnias indígenas que habitam o sudoeste dos Estados Unidos (Arizona e Novo México). Os povos mais conhecidos são os Hopi, os Zunhi e os Kere. As suas crianças são moldadas de acordo com a tradição de seu povo, logo são consideradas uniformes e homogêneas para Benedict, exprimindo uma relação entre adulto-criança de comprometimento com a educação. Os Pueblo não cultivam o excesso de forma alguma, não toleram a violência, não se entregam ao exercício da autoridade nem gostam de situações em que se veem sozinhos. Sendo assim tanto no âmbito religioso quanto no doméstico, não há exercício da autoridade, pois o objetivo consiste em entranhar o indivíduo no grupo.

Enquanto que, na cultura Zunhi, as crianças são mimadas. Os Zuhni são uma tribo norteamericana e vivem no povoado Zuni, no oeste do estado do Novo México e fica a $55 \mathrm{~km}$ ao sul da cidade de Gallup. Atualmente tem uma população de 12 mil pessoas. Muitos pesquisadores acreditam que os Zuhni são descendentes dos antigos povos Pueblos que moravam no deserto do Novo México. Na cultura Zunhi, "a responsabilidade e o poder estão sempre distribuídos e o grupo passa a ser a unidade funcional. O modo aceito de aproximação ao sobrenatural é o ritual grupal. O modo aceito de garantir a subsistência da familia é a parceria no lar" (BENEDICT, 2013, p.78).

Sem autoridade, nenhum adulto do povo Zunhi disciplina as crianças de sua família. Atitude essa que resulta em homens que mimam muito os bebês. A consequência da falta de autoridade faz com que a criança cresça sem os ressentimentos de ambição para com seus familiares. Depois, quando se torna adulto, o menino não tem motivações que o levem a imaginar situações em que a autoridade seja relevante.

Ao contrário dos Zuni, os Dobu são anárquicos e dionisíacos, indisciplinados e traiçoeiros, cuja organização social é anárquica. Os Dobu estão localizados na Ilha da Melanésia de Dobu, vivem da subsistência seu principal cultivo é o inhame. Os Dobu ganhavam dinheiro fazendo copra, mas a mão-deobra migratória nas plantações e nas minas de ouro era a mais importante fonte de dinheiro durante a era colonial, e se tornou um rito essencial de passagem para os jovens. Os Dobu tornaram-se cristãos, devido às intensas missões no século XIX.

9 O conceito de patterns refere-se à forma característica que levam os vários componentes de uma cultura ou de uma sociedade, atrelada às atitudes de seus membros, englobando assim noções de uso, costume, e a moral de reconhecer a originalidade de uma cultura (PANOFF e PERRIN, 1973). 
Benedict (2013) conclui que o povo Dobu é austero, pudico e apaixonado, consumido pelo ciúme, a suspeita e o ressentimento, e assim a vida em Dobu "encoraja formas extremas de animosidade e malvadeza [...] vivenciando sem repressão os piores pesadelos do homem sobre a maldade do universo e, de acordo com sua visão de vida a virtude consiste em escolher uma vítima na qual ele possa dar vazão à maldade que atribui tanto à sociedade humana quanto às forças da natureza” (BENEDICT, 2013, p. 121).

Os Kwakiutl, por outro lado, têm uma personalidade moldada pela dominância, cuja configuração particular, dominada por um todo integral e funcional, forçosamente original e irredutível a qualquer outro, é dominada por um patterns geral, explica Erny (1982). Os Kwakiutl são da Ilha de Vancouver, na costa do Oceano Pacífico no Canadá. Sua economia era baseada na pesca, caça e colheita de frutos silvestres, assim como, a tecelagem e a marcenaria eram importantes ofícios.

Entre os Kwakiutl há um sistema de hierarquia, no qual a ideia de competição é perpassada de geração em geração.

Esta, meu filho, é a senda que teu pai traçou para ti e que tu deves seguir. Teu pai não era homem comum. Era um verdadeiro chefe koskimo. Faz como teu pai fez. Rasga as mantas com botões ou entrega-as à tribo que é nossa rival. Apenas isso. O filho respondeu: não fecharei a senda que meu pai traçou para mim. Não violarei a lei que meu chefe estabeleceu para mim. Dou estas mantas aos meus rivais. A guerra em que hoje nos enfrentamos é doce e forte (ERNY, 1982, p. 139).

O sentido dos títulos de nobreza que realçam a hierarquia, na transmissão dos costumes de geração em geração, faz sentido entre os Kwakiutl, logo a competição e a rivalidade serão perpetuadas e transmitidas de pai para filho.

Em Crisântemo e a Espada, Benedict (1972) explica que há também, entre os japoneses, uma padronização dos seus costumes e valores para a preservação da hierarquia que perpassa por diversas instituições japonesas como a família, o Estado, a vida religiosa e econômica, decorrentes de sua história nacional feudal, de uma sociedade rígida de classe e casta e de hábitos seculares. É na família que o respeito às regras da hierarquia tem início.

Enquanto a mãe ainda leva o bebê preso às costas, empurra-lhe a cabeça para baixo com a mão e suas primeiras lições consistem na observância de um procedimento respeitoso com relação ao pai ou ao irmão mais velho. A esposa inclina-se diante do marido; a criança diante do pai; os irmãos mais jovens, diante dos mais velhos e a irmã, diante de todos os irmãos, qualquer que seja a sua idade (BENEDICT, 1972, p. 48).

Esses gestos não significam algo vazio, mas o inclinar para o outro significa reconhecer o direito do outro de interferir em sua vida, pois a hierarquia baseada no sexo, geração e primogenitura constitui parte da vida familiar. Assim, "qualquer que seja a idade, a posição de cada um na hierarquia depende do fato de ser homem ou mulher. A mulher japonesa caminha atrás do marido e tem uma posição inferior" (BENEDICT, 1972, p. 51).

A hierarquia, a obediência à ordem e o respeito aos mais velhos são atitudes marcantes na cultura japonesa, cujo objetivo consiste em promover o equilíbrio psicológico na primeira infância para que se torne um adulto cheio de virtudes. É notável que a primeira infância seja marcada por uma vida 
despreocupada e um momento em que as crianças não "sentem vergonha". Já a partir dos 6/7 anos, a criança é marcada por rejeição, censura, "sentem vergonha", de modo a se igualar às pessoas adultas.

A virtude e a autorresponsabilidade são muito valorizadas no Japão, pois há uma valorização pela perfeição e virtuosismo. Neste sentido, para o japonês a espada torna-se, não um símbolo de agressão, mas sim uma analogia do homem ideal e autorresponsável. Os japoneses exigem muito de si para evitar o ostracismo e a difamação e, "tais atitudes, aprendidas pela criança desde as primeiras experiências com o pai, elabora-se um padrão para toda a sociedade japonesa, marcando o respeito por sua posição hierárquica" (BENEDICT, 1972, p. 252).

De acordo com Benedict em Continuidades e Descontinuidades no Condicionamento Cultural10, somos condicionados a ter tais comportamentos e atitudes, caso o comportamento não esteja enquadrado dentro dos padrões daquela cultura, seremos considerados como "anormais" ou que ocorreu uma descontinuidade no condicionamento de tal pessoa em tal cultura. Nesse condicionamento é exercido o papel do status responsável, ou seja, são adotadas técnicas para que a criança seja responsável por suas tarefas e essencial para o treinamento infantil. Os Ojibwa canadenses apresentam os resultados da continuidade do condicionamento cultural. Eles são o terceiro maior grupo de nativos americanos nos Estados Unidos e vivem por todo o norte de Michigan e no Canadá. Eles vivem uma vida sedentária e praticam a pesca, a caça, o cultivo do milho e abóbora e da colheita do Manoomin. Eles desenvolveram uma forma de escrita pictórica usada em rituais religiosos gravadas em pergaminhos de casca de bétula.

Essa tribo tem como características,

[...] tira seu sustento durante as armadilhas de caça no inverno, e a pequena família do pai, mãe, e crianças vive sozinha durante o longo inverno em suas grandes áreas congeladas de caça. O menino acompanha seu pai e traz em sua captura a sua irmã, e o pai traz a sua mãe, a garota prepara a carne e as peles para ele, assim como a mãe faz para o seu marido. Quando o menino estiver com doze anos, ele pode ter feito sua própria linha de armadilhas em seu próprio território de caça e retornar para casa dos pais apenas uma vez durante vários meses - ainda trazer a carne e as peles para sua irmã. A jovem criança é ensinada consistentemente que tem a ela própria para contar na vida, e isto é tão verdade nas relações que terá com o sobrenatural quanto o negócio de obter o sustento. Essa atitude ele aceitará como um adulto bem-sucedido assim como aceitou quando criança (BENEDICT, 1953, p.24, tradução nossa).

O status de responsável demonstra a continuidade do condicionamento cultural para a permanência do patterns daquela cultura. Em algumas culturas, a criança aprende a ter responsabilidade desde pequenas, mas em outras, como a norte-americana, ocorre a confusão de comportamentos entre adulto e criança. A criança quando pequena pode tudo e é livre, mas quando cresce, torna-se adulto, lhe é exigido que assuma muitas responsabilidades. Nesse caso, há um desencadeamento e descontinuidade de comportamentos (BENEDICT, 1934), pois os adultos não sabem qual papel exercer, e consequentemente, seus filhos não sabem qual comportamento imitar, gerando o uso da dominação e da

\footnotetext{
10 Este artigo foi um esforço por parte da Ruth Benedict de aplicar à sua própria sociedade considerações baseadas nas observações de antropólogos de campo, a qual seu interesse originalmente tinha sido esboçado pelas descontinuidades extremas da cultura Manus. É esclarecedor sobre o cruzamento cultural tradicional de um problema em nossa própria cultura. - (Margaret Mead em Childhood in Contemporany Cultures).
} 
punição para alcançar os objetivos na educação daquela criança. A padronização no comportamento é fundamental para que a cultura perpetue e permaneça por muitas gerações. A descontinuidade de comportamentos da cultura norte-americana demonstra como no país não existem padrões a serem seguidos, principalmente, devido às inúmeras influências recebidas dos imigrantes que lá foram morar.

\section{Considerações finais}

Os estudos da Escola de Cultura e Personalidade tinham como foco entender as crianças e adolescentes em outras realidades socioculturais, tomando frequentemente a sociedade norte-americana da época como um contraponto. Mead e Benedict partiram da definição de cultura para explicar o que é propriamente cultural e, portanto, particular, e o que é natural e, portanto, universal, no comportamento humano, logo a cultura é definida como aquilo que é transmitido entre gerações e aprendido pelos membros da sociedade. Nessa escola de pensamento é dada ênfase à formação da personalidade: a relação do indivíduo com a sociedade em termos de sua formação como um tipo específico de personalidade. Essa relação construída na passividade receptora da criança e na insistência em manter os costumes do passado apresenta implicações nas relações adulto-criança, pois mostra uma criança passiva e sem autonomia em detrimento dos costumes e valores dos adultos.

Esses trabalhos trouxeram contribuições no estudo da criança, explica Cohn (2002), demonstrando que a experiência das crianças é cultural e só pode ser entendida em seu contexto, no entanto, corre-se o risco de provocar a cisão entre a vida adulta e a da criança, condicionando à formação do adulto ideal, e à criança sempre como um ser imaturo e em desenvolvimento. Há padrões de cultura que moldam a personalidade dos indivíduos que vivem em determinado grupo sociocultural e determinam como as relações entre adulto e criança devem acontecer.

Esses estudos mostram que na relação adulto e criança é assumida uma postura de relação hierárquica em que o lugar do adulto é assumido como superior ao da criança em detrimento da perpetuação dos valores a serem transmitidos de geração em geração. No entanto, se for observado a dinamicidade educacional consiste na perpetuação dos valores e não na modificação deles. Outro ponto relevante a ser observado nos trabalhos de Mead e Benedict é a perspectiva universalista imbuída de preceitos psicológicos presente nas descrições dos povos estudados. Pode-se supor que esses preceitos psicológicos e comportamentais tão difundidos em seus trabalhos tenham de alguma maneira influenciado a forma de se pensar a criança em relação ao adulto e a educação. Porque Mead e Benedict contraporem a cultura norte-americana com a dos "povos primitivos" e ressaltarem nesses povos os seus pontos positivos em comparação com a deterioração da cultura norte-americana, nos apresenta um entendimento de que a relação de submissão da criança para com o adulto é importante para uma sociedade saudável.

As abordagens de Mead e de Benedict remetem à ideia de ser humano ideal ou a perfectibilidade. As imagens do ser humano dependem de aspectos históricos e culturais da vida cotidiana, em que várias 
imagens do ser humano foram formadas na história. É interessante observar como as imagens do ser humano estão ligadas ao seu contexto histórico e cultural e como as diferentes imagens do ser humano levam a diferentes concepções de educação.

No entanto, essas imagens do ser humano produzem efeitos na educação, como por exemplo, a tentativa por meio da educação de tornar o ser humano perfeito, a perfectibilidade, e a hipótese oposta da qual seria impossível mudar o ser humano por meio da educação, a perfectibilidade individual, explicita Wulf $(2001 ; 2005)$. O tornar o ser humano perfeito, ou seja, criar a imagem ideal do ser humano perfeito, por meio da educação, está vinculado ao sonho constitutivo da época moderna, que consequentemente está ligada ao significado da imaginação para a sociedade e para o indivíduo, pois o ser humano tem necessidade de sonho e utopia para evoluir e nesse processo a educação tem papel decisivo. Comenius no início do período moderno concebeu a utopia sobre a possibilidade de tornar o homem perfeito: $a$ arte universal de ensinar tudo a todos, acompanhada pelas utopias de Rousseau, Pestalozzi, Herbart e Schleiermacher, apesar de suas diferenças. No entanto, mudar o homem não é tão fácil, e essas utopias tiveram dificuldades de concretização.

As imagens históricas do ser humano produzem efeitos na educação e por meio dos sonhos e utopias está claro que sempre houve a tentativa de conceber a imagem do ser humano ideal, ou a imagem perfeita, seja por preceitos religiosos, individualistas, universalistas, autônomos, renovadores e/ou vinculados à realidade social.

Por isso, apresento mais indagações a respeito da relação adulto-criança: $\mathrm{O}$ que isso nos ajuda a pensar sobre os estudos sobre crianças nos dias de hoje? Como são estabelecidas as relações entre adulto e criança, seja no meio familiar, no meio educacional, na sociedade ou no processo educacional? Como as relações entre adulto e criança estão institucionalizadas nos dias de hoje? O que a perspectiva da antropologia e da antropologia educacional contemporânea tem a contribuir para os estudos da criança e das relações adulto-criança?

Pensar a criança envolve aspectos que ultrapassam as visões reducionistas que se aplicam à educação e que ocorrem em um determinado grupo social, envolvendo além dos aspectos religiosos, míticos, musicais, organizacionais, diz respeito à relação adulto-criança. Há de se pensar que a educação não acontece somente com o adulto ou tão somente com a criança, mas nessa troca de conhecimentos e valores que ultrapassam gerações e que são repassados e recriados a cada nova geração. Haverá uma troca entre adulto e criança, ambos aproveitarão desse intercâmbio, e muito da parte dos adultos será repensado e redimensionado, a partir dos questionamentos das crianças e dos adolescentes. Assim, a relação entre adulto e criança será construída entre o desejo da criança se tornar semelhante ao adulto, mas, ao mesmo tempo, ao desejo de ser um ser único, diferente do outro. 


\section{Referências}

BENEDICT, Ruth. Continuities and Discontinuities in Cultural Conditioning. In: KLUCKHOHN, Clyde; MURRAY, Henry. Personality: in nature, society and culture. London: Jonathan Cape Thirty Bedford Square, 1953. p. 522-531.

BENEDICT, Ruth. O Crisântemo e a Espada: Padrões da Cultura Japonesa. São Paulo: Editora Perspectiva, 1972.

BENEDICT, Ruth. Padrões de cultura. Petrópolis, R.J.: Vozes, 2013.

BENEDICT, Ruth. Anthropology and the Abnormal. The Journal of General Psychology, vol. 10, $\mathrm{n}^{\circ}$ 1, 59-82, 1934

COHN, Clarice. A criança, o aprendizado e a socialização na antropologia. In: SILVA, Aracy Lopes da; MACEDO, Ana Vera; NUNES, Angela. (Orgs.) Crianças indígenas: Ensaios antropológicos. São Paulo: Global, 2002.

COHN, Clarice. Antropologia da criança. 2a ed. Rio de Janeiro: Jorge Zahar, 2009.

ERNY, Pierre. Etnologia da educação. Rio de Janeiro: Zahar Editores, 1982.

MEAD, Margaret. Coming of age in Samoa: a psychological study of primitive youth for Western Civilisation. New York: William Morrow \& Company, 1928.

MEAD, Margaret. Growing up in New Guinea: a comparative study of primitive education. New York: Blue Ribbon Books, 1930.

MEAD, Margaret. Age patterning in Personality development. American Journal of Orthopsychiatry. New York, april, vol. 17, nº 2, 231 - 240, 1947.

MEAD, Margaret. Ruth Fulton Benedict - 1887-1948. American Anthropologist. Arlington, Virginia, jul./sep., vol. 51, no 3, 457 - 468, 1949.

MEAD, Margaret. Culture and commitment: A study of the generation gap. New York: Natural History Press / Doubleday \& Company, 1970.

MEAD, Margaret. Sexo e Temperamento. Série Debates - Antropologia. São Paulo: Perspectiva, 1979.

NUNES, Angela. O lugar da criança nos textos sobre sociedades indígenas brasileiras. In: SILVA, Aracy Lopes; MACEDO, Ana Vera; NUNES, Angela (Orgs.). Crianças indígenas: ensaios antropológicos. São Paulo: Global, 2002.

PIRES, Flavia. O que as crianças podem fazer pela Antropologia? Horizontes Antropológicos. Porto Alegre, ano 16, jul./dez., s/v, n 34, 137-157, 2010. 
TEDRUS, Dora. A relação adulto-criança: um estudo antropológico em creches e escolinhas de

Campinas. Campinas: Unicamp, 1998.

WULF, Christoph. Einführung in die Anthropologie der Erziehung. Weinheim/Basel: Beltz, 2001.

WULF, Christoph. Antropologia da Educação. Tradução de Sidney Reinaldo da Silva. Campinas - S.P.: Editora Alínea, 2005. 